\title{
Differences in Parents' and Teachers' Ratings of ADHD Symptoms and Other Mental Health Problems
}

\author{
Vaya Papageorgiou* \\ Efrosini Kalyva** \\ Vaios Dafoulis*** \\ Panos Vostanis ${ }^{\star \star \star *}$
}

* Department of Psychiatry, University of Ioannina School of Medicine, 100 - Greece

** City Liberal Studies, Thessaloniki, Greece

*** Medical Psycho-Pedagogical Centre of North Greece, Psychiatric Hospital of Thessaloniki, Greece

**** Greenwood Institute of Child Health, Department of Psychiatry Division of Child Psychiatry, Leicester, UK

\begin{abstract}
Background and objectives: Attention-Deficit/Hyperactivity Disorder (ADHD) symptoms and other mental health problems appear early in life and proper treatment is essential for a positive long-term outcome. The present study examines the level of agreement, and potential gender differences, between parents' and teachers' reports of ADHD symptoms and other mental health problems in 305 Greek children aged between 6-9 years.

Methods: Parents and teachers of 147 boys and 158 girls attending the first three grades of 10 primary schools in the wider area of Northern Greece completed the Strength and Difficulties Questionnaire (SDQ- Goodman, 1997) and the Child Attention Profile (CAPBarkley, 1990).

Results: The level of agreement between parents' and teachers' reports was low to moderate for the SDQ (0.16-0.34) and satisfactory for the CAP (0.60-0.66). Parents reported more hyperactivity, emotional, and conduct problems than teachers according to SDQ and more overactivity and attention-deficit with hyperactivity according to CAP. Gender differences in ratings were found as well, since boys were reported as being more hyperactive according to SDQ and as having more overactivity and attention-deficit with hyperactivity according to CAP than girls.

Conclusions: Findings are discussed in terms of the importance of using multiple informants to gather data on disruptive behaviour through rating scales.
\end{abstract}




\section{Introduction}

Attention-Deficit/Hyperactivity Disorder (ADHD) is one of the most common neurobehavioural disorders of childhood and among the most prevalent chronic health conditions affecting school-aged children ${ }^{1}$. It is characterised by developmentally inappropriate levels of motor activity, difficulty in sustaining attention, and impulsivity ${ }^{2}$. ADHD transcends the limits of childhood; prospective clinical studies and longitudinal studies have shown that the symptoms and the accompanying impairment often persist well into adult life ${ }^{3}$.

Prevalence of ADHD depends on the diagnostic criteria used, the diagnostic measures, the sampling method, the number of informants, as well as the age and the nature of the population studied ${ }^{4}$. Screening with questionnaires identifies 10-20\% of the population as affected ${ }^{5}$, while studies focused on ADHD using definitions based on DSM report prevalence rates from 5$10 \%$. A recent review of prevalence rates in school-aged community samples indicates rates varying from $4 \%$ to $12 \%$ (median: $5.8 \%)^{7}$.

Children with ADHD usually have functional impairment across multiple settings and are at risk for long-term adverse effects on social-emotional development, academic performance, interpersonal relationships with family members and peers ${ }^{8-}$ 11. Other mental health problems that might manifest are anxiety disorders ${ }^{12}$, oppositional defiant disorder or conduct disorder ${ }^{13}$, and reading disabilities ${ }^{14}$ and they tend to vary with age; in young children there is an overlap between ADHD symptoms and other neuropsychiatric and developmental conditions ${ }^{15}$. Older children and adolescents exhibit usually anxiety disorders, depression, bipolar disorder, substance abuse, and antisocial personality disorder ${ }^{16,17}$. The identification of these mental health problems is extremely important for diagnosis and treatment, since they may affect the main symptoms of $\mathrm{ADHD}^{18}$.

DSM-IV criteria for ADHD require that both symptoms and impairment from those symptoms be exhibited in at least two settings ${ }^{19}$. Therefore, it is common practice to collect data using both parent and teacher reports that are regarded as optimal for the screening of externalising behaviours, such as $\mathrm{ADHD}^{20}$, since the behaviour of the children is recorded both at home and at school $^{21,22}$. Teachers observe daily many children who are at the same developmental level and can thus spot behaviours that are not age-appropriate ${ }^{23}$, while parents are able to provide more valid information about behaviours at home ${ }^{24}$. Although parents' reports are considered to be as sensitive as teachers' in detecting changes in their children's ADHD symptoms ${ }^{25}$, the average correlation between scores obtained from multiple informants (parent, teacher, and self report) was moderate $0.28^{26-27}$. Therefore, the aim of this study is to determine the levels of agreement between parents' and teachers' reports of children's ADHD symptoms and other mental health problems in Greek primary schoolchildren. Moreover, since in the general population $9.2 \%$ of males and $2.9 \%$ of females are found to have behaviours consistent with $\mathrm{ADHD}^{28-30}$, and boys are identified with ADHD at least four times as often as girls in general populations ${ }^{31}$, gender differences in ratings will be explored as well. It is expected that parents and teachers will rate boys as having more ADHD symptoms and other mental health problems than girls. 


\section{Methods}

\section{Participants and sampling proce- dures}

The sample was taken from 10 public elementary schools in the municipality of Thessaloniki, Greece, which were drawn randomly from selected areas of both high and low socio-economic status. The researchers contacted Educational Authorities in order to get the permission to approach the schools' principals and to brief them about the aim of the study. With the principals' authorisation, in every school a class from each of the first three grade levels was randomly selected and twelve pupils (six boys and six girls) were randomly identified by a prepared list of random numbers. This process was necessary to ensure an equal distribution of participants according to their age and gender (a total of 360 pupils -120 children per grade). The next step was to send a letter to the parents of each selected child explaining the purpose of the research, a consent form, and two questionnaires to fill in at home. The teachers of the selected children were also asked to complete a consent form and to fill in the two corresponding questionnaires.

A total of 660 of the 720 questionnaires that were distributed to the teachers (response rate of $91.7 \%$ ) and a total of 617 out of the 720 questionnaires that were distributed to the parents (response rate of
$86 \%$ ) were returned completed and were included in the study. Therefore, data was collected from the parents and teachers of 305 out of the 360 schoolchildren that were initially selected (attrition: 15.3\%). There were 147 boys and 158 girls, aged between 6 and 9 years old (mean age $=7$ years and 36 months). The distribution of the sample is shown on Table I. Since initial analyses showed that there were no age differences in the frequency of ADHD symptoms (for SDQ, $\left.F_{(2,300)}=2.29, p>0.05\right)$ and other mental health problems (for CAP, $F_{(2,300)}=$ $1.47, p>0.05)$, this variable was not further explored.

\section{Measures}

The parents and the teachers of the selected children completed two questionnaires, the Strengths and Difficulties Questionnaire $(\mathrm{SDQ})^{32}$ and the Child Attention Profile $(\mathrm{CAP})^{33}$. The SDQ is a measure of social, emotional and behavioural functioning. It has been used widely in many cultures such as Australia ${ }^{34}$, Germany ${ }^{35}$, and the Nordic countries $^{36}$. It has also been translated and standardised into Greek ${ }^{37}$. SDQ is a brief screening measure that includes parent and teacher version for children 4-16 year, selfreport version for adolescents 11-16 years and a parent and preschool professional version for 3-4 year-olds. This instrument produces scores for hyperactivity, emotional problems, conduct problems, peer prob-

Table I

Distribution of the sample by grade and by gender

\begin{tabular}{lccc} 
& \multicolumn{2}{c}{ Gender } & Total \\
\hline Grades & Boys & Girls & 82 \\
Grade 2 & 46 & 36 & 119 \\
Grade 3 & 55 & 64 & 104 \\
\hline
\end{tabular}


lems, and prosocial behaviour (the latter was not included in the present study). Each subscale consists of five items. Each item has the response option of 0 (not at all), 1 (a little, sometimes) or 2 (very much, all of the time $)^{5}$. The reliability of the scale for the present study was $\alpha=0.79$, which is considered to be satisfactory.

CAP has been translated from English into Greek by one child psychiatrist and one psychologist who were fluent in both languages. In order to ensure that the translation was accurate, it was translated independently back into English by two other child psychologists. The translation was well received by the parents and the teachers who were asked to complete the questionnaires. CAP is designed based on the Child Behaviour Checklist and it consists of 12 items in two subscales of inattention (seven items) and overactivity (5 items). Parents and teachers rate the behaviour of the children by using a 3-point Likert scale from 0 (never/rarely) to 2 (always). Three scores can be derived from CAP: inattention, overactivity, and total score referring to attention-deficit with hyperactivity. The reliability of the scale for the present study was $\alpha=$ 0.91 , which is extremely satisfactory.

\section{Results}

Correlations (Pearson) were used to determine the levels of agreement between parents' and teachers' reports of children's ADHD symptoms and other mental health problems. Statistically significant positive correlations were found between parents' and teachers' ratings on both SDQ: hyperactivity $r(305)=0.31, p<0.001$, emotional problems $r(305)=0.16, p<0.01$, conduct problems $r(305)=0.28, p<0.001$, peer problems $r(305)=0.34, p<0.001$ (see Table II); and CAP: overactivity $r(305)=0.64, p<$ 0.001 , inattention $r(305)=0.60, p<0.001$, and attention-deficit with hyperactivity $r$ $(305)=0.66, p<0.001$ (see Table III).

Moreover, a statistically significant correlation was found between parents' ratings on the hyperactivity subscale of SDQ and their ratings on CAP overactivity $r(305)=$ $0.51, p<0.001$, CAP inattention $r(305)=$ $0.48, p<0.001$, and CAP attention-deficit with hyperactivity $r(305)=0.55, p<0.001$. A statistically significant correlation was found also between teachers' ratings on the hyperactivity subscale of SDQ and their ratings on CAP overactivity $r(305)=0.59, p<$

Table II

Correlations between parents' and teachers' ratings on SDQ

\begin{tabular}{|c|c|c|c|c|c|c|c|c|}
\hline & 1 & 2 & 3 & 4 & 5 & 6 & 7 & 8 \\
\hline \multicolumn{9}{|l|}{ Parents } \\
\hline 1. Hyperactivity & 1 & & & & & & & \\
\hline 2. Emotional problems & $0.29 *$ & 1 & & & & & & \\
\hline 3. Conduct problems & $0.48 *$ & $0.24 *$ & 1 & & & & & \\
\hline 4. Peer problems & 0.07 & $0.24 *$ & $0.12 * *$ & 1 & & & & \\
\hline \multicolumn{9}{|l|}{ Teachers } \\
\hline 5. Hyperactivity & $0.31 *$ & -0.07 & $0.21 *$ & 0.07 & 1 & & & \\
\hline 6. Emotional problems & 0.09 & $0.16^{*}$ & 0.03 & $0.16^{*}$ & $0.24 *$ & & & \\
\hline 7. Conduct problems & $0.13 * *$ & -0.03 & $0.28 *$ & 0.09 & $0.50^{*}$ & 0.11 & 1 & \\
\hline 8. Peer problems & $0.18^{*}$ & 0.06 & 0.09 & $0.34 *$ & $0.38 *$ & $0.45^{*}$ & $0.21 *$ & 1 \\
\hline
\end{tabular}

$* \mathrm{p}<0.01$

$* * \mathrm{p}<0.05$ 
Table III

Correlations between parents' and teachers' ratings on CAP

\begin{tabular}{lllllll} 
& 1 & 2 & 3 & 4 & 5 & 6 \\
\hline Parents & & & & & \\
$\quad$ 1. Overactivity & 1 & & & & \\
$\quad$ 2. Inattention & $0.62^{*}$ & 1 & & & \\
$\quad$ 3. Attention-deficit with hyperactivity & $0.87^{*}$ & $0.87^{*}$ & 1 & & & \\
\hline Teachers & & & & & \\
$\quad$ 1. Overactivity & $0.64^{*}$ & $0.43^{*}$ & $0.60^{*}$ & 1 & \\
$\quad$ 2. Inattention & $0.44^{*}$ & $0.60^{*}$ & $0.57^{*}$ & $0.60^{*}$ & 1 \\
$\quad$ 3. Attention-deficit with hyperactivity & $0.59^{*}$ & $0.57^{*}$ & $0.66^{*}$ & $0.87^{*}$ & $0.91^{*}$ & 1 \\
\hline * $<0.01$ & & & & &
\end{tabular}

0.001, CAP inattention $r(305)=0.47, p<$ 0.001 , and CAP attention-deficit with hyperactivity $r(305)=0.57, p<0.001$.

Since SDQ hyperactivity subscale includes five items covering inattention, hyperactivity, and impulsivity, high correlation between SDQ and the three CAP subtypes is expected. Therefore, it was decided to measure the correlation between the different CAP subtypes, for parents' and teachers' ratings, which were as follows: a) parents' ratings on overactivity and inattention $r(305)=0.62, p<0.001$, on overactivity and attention-deficit with hyperactivity $r$ $(305)=0.87, p<0.001$, and on inattention and attention-deficit with hyperactivity $r$ $(305)=0.87, p<0.001$, and $b)$ teachers' ratings on overactivity and inattention $r$ (305) $=0.60, p<0.001$, on overactivity and attention-deficit with hyperactivity $r$ (305) = $0.87, p<0.001$, and on inattention and attention-deficit with hyperactivity $r(305)=$ $0.91, p<0.001$ (see Table III).

Despite these positive correlations, there were some differences in parents' and teachers' ratings according to paired-samples ttest. More specifically, parents reported statistically significant higher hyperactivity $\left(t_{(304)}=3.41, p<0.005\right)$, emotional problems $\left(t_{(304)}=5.57, p<0.001\right)$, and conduct problems $\left(t_{(304)}=2.84, p<0.05\right)$ according to SDQ, and higher overactivity $\left(t_{(304)}=\right.$ 5.40, $p<0.001)$ and attention-deficit with hyperactivity $\left(t_{(304)}=3.63, p<0.001\right)$ according to CAP than teachers. Parents and teachers did not report any statistically significant differences in terms of peer problems $\left(t_{(304)}=1.64, p>0.05\right)$ according to SDQ and inattention $\left(t_{(304)}=-1.44, p>0.05\right)$ according to CAP (see Table IV).

Preliminary analysis showed that there were no age differences in terms of parents' and teacher's ratings of ADHD symptoms and other mental health problems, however gender differences were detected. More specifically (see Table V), parents reported that boys exhibited statistically significant higher hyperactivity $\left(F_{(1,301)}=13.18, p<\right.$ $0.001)$ than girls, while no gender differences were found for emotional problems $\left(F_{(1,301)}=0.19, p>0.05\right)$, conduct problems $\left(F_{(1,301)}=2.13, p>0.05\right)$, and peer problems $\left(F_{(1,301)}=0.83, p>0.05\right)$. Teachers reported that boys exhibited statistically significant higher hyperactivity $\left(F_{(1,301)}=15.36\right.$, $p<0.001)$ and conduct problems $\left(F_{(1,301)}=\right.$ 19.91, $p<0.001)$ than girls, while there were no gender differences in emotional problems $\left(F_{(1,301)}=0.83, p>0.05\right)$ and in peer problems $\left(F_{(1,301)}=0.87, p>0.05\right)$. 


\section{Table IV}

Means and standard deviations (s.d.) of ADHD symptoms and other mental health problems in Greek children aged 6-9 years according to their parents and teachers

\begin{tabular}{|c|c|c|c|}
\hline & $\begin{array}{l}\text { Parents } \\
\text { M (s.d.) }\end{array}$ & $\begin{array}{l}\text { Teachers } \\
\text { M (s.d.) }\end{array}$ & $t$ \\
\hline \multicolumn{4}{|l|}{ SDQ } \\
\hline $\begin{array}{l}\text { Hyperactivity } \\
\text { 1. Restless, overactive, cannot stay still for long } \\
\text { 2. Constantly fidgeting or squirming } \\
\text { 3. Easily distracted, concentration wanders } \\
\text { 4. Thinks things out before acting } \dagger \\
\text { 5. Sees tasks through to the end, good attention span } \dagger\end{array}$ & $3.10(1.88)$ & $2.51(2.27)$ & $3.41 *$ \\
\hline $\begin{array}{l}\text { Emotional problems } \\
\text { 1. Often complains of headaches, stomach-aches or sickness } \\
\text { 2. Many worries, often seems worried } \\
\text { 3. Often unhappy, down-hearted or tearful } \\
\text { 4. Nervous or clingy in new situations, easily loses confidence } \\
\text { 5. Many fears, easily scared }\end{array}$ & $2.29(1.29)$ & $1.54(1.29)$ & $5.57 * *$ \\
\hline $\begin{array}{l}\text { Conduct problems } \\
\text { 1. Often has temper tantrums or hot } \\
\text { 2. Generally obedient, usually does what adults request } \dagger \\
\text { 3. Often fights with other children or bullies them } \\
\text { 4. Often lies or cheats } \\
\text { 5. Steals from home, school or elsewhere }\end{array}$ & $1.67(1.09)$ & $1.35(1.18)$ & $2.84 * * *$ \\
\hline $\begin{array}{l}\text { Peer problems } \\
\text { 1. Rather solitary, tends to play alone } \\
\text { 2. Has at least one good friend } \dagger \\
\text { 3. Generally liked by other children } \dagger \\
\text { 4. Picked on or bullied by other children } \\
\text { 5. Gets on better with adults than with other children }\end{array}$ & $1.19(0.98)$ & $1.32(1.27)$ & -1.44 \\
\hline
\end{tabular}

\section{CAP}

Overactivity

1. Can't sit still, restless, or hyperactive

$3.04(2.27)$

$2.31(1.70)$

$5.40 * *$

2. Fidgets

3. Impulsive or acts without thinking

4. Messy work

5. Talks too much

Inattention

1.64

1. Can't concentrate, can't pay attention for long

2. Daydreams or gets lost in his/her thoughts

3. Inattentive, easily distracted

4. Difficulty following directions

5. Fail to carry out assigned tasks

Attention-deficit with hyperactivity

All of the above 10 items

$\dagger$ These items are scored reversely

$* \mathrm{p}<0.005$

$* * \mathrm{p}<0.001$

$* * * \mathrm{p}<0.05$ 
Table V

Means and standard deviations (s.d.) of ADHD symptoms and other mental health problems in Greek boys and girls aged 6-9 years according to their parents and teachers

\begin{tabular}{lccc} 
& Boys & Girls & \\
& M (s.d.) & M (s.d.) & $F$ \\
\hline SDQ - Parents & & & \\
Hyperactivity & $3.59(1.97)$ & $2.62(1.66)$ & $13.18^{*}$ \\
Emotional problems & $2.24(1.21)$ & $2.33(1.37)$ & 0.19 \\
Conduct problems & $1.81(1.01)$ & $1.54(1.16)$ & 2.13 \\
Peer problems & $1.26(0.96)$ & $1.11(0.94)$ & 0.83 \\
SDQ - Teachers & & & \\
Hyperactivity & $3.11(2.62)$ & $1.90(1.74)$ & $15.36^{*}$ \\
Emotional problems & $1.44(1.21)$ & $1.62(1.34)$ & 0.83 \\
Conduct problems & $1.78(1.42)$ & $0.94(0.82)$ & $0.91^{*}$ \\
Peer problems & $1.42(1.23)$ & $1.24(1.18)$ & 0.87 \\
\hline
\end{tabular}

$* \mathrm{p}<0.001$

As far as ADHD symptoms are concerned (see Table VI), parents reported that boys exhibited statistically significant higher overactivity $\left(F_{(1,301)}=23.17, p<0.001\right)$ and attention-deficit with hyperactivity ( $F$ $(1,301)=8.85, p<0.05)$ than girls, while no gender differences were found for inatten- tion $\left(F_{(1,301)}=1.60, p>0.05\right)$. Teachers reported that boys exhibited statistically significant higher overactivity $\left(F_{(1,301)}=\right.$ $11.22, p<0.05)$, inattention $\left(F_{(1,301)}=\right.$ $4.27, p<0.05)$, and attention-deficit with hyperactivity $\left(F_{(1,301)}=8.11, p<0.05\right)$ than girls.

\section{Table VI}

Means and standard deviations (s.d.) of ADHD symptoms in Greek boys and girls aged 6-9 years according to their parents and teachers

\begin{tabular}{lccc} 
& Boys & Girls & \\
& M (s.d.) & M (s.d.) & $F$ \\
\hline CAP - Parents & & & \\
$\quad$ Overactivity & $3.80(2.52)$ & $2.32(1.82)$ & $23.17^{*}$ \\
$\quad$ Inattention & $3.72(2.61)$ & $3.26(2.68)$ & 1.60 \\
$\quad$ Attention-deficit with hyperactivity & $7.35(4.90)$ & $5.57(4.53)$ & $8.85^{* *}$ \\
CAP- Teachers & & & \\
$\quad$ Overactivity & $2.84(2.63)$ & $1.79(1.56)$ & $11.22^{* *}$ \\
Inattention & $3.60(2.78)$ & $2.83(2.63)$ & $4.27^{* *}$ \\
Attention-deficit with hyperactivity & $6.42(5.09)$ & $4.67(4.60)$ & $8.11^{* *}$ \\
\hline
\end{tabular}

$* \mathrm{p}<0.001$

$* * \mathrm{p}<0.05$ 


\section{Discussion}

The present study explored the level of agreement between parents' and teachers' reports of children's ADHD symptoms and other mental health problems. The level of agreement for mental health problems, as measured by the SDQ, varied from a low 0.16 for emotional problems to a moderate 0.31 for conduct problems and a 0.34 for peer problems. Parents reported more emotional and conduct problems than teachers, while no difference was found for peer problems. This finding corresponds to the observation by Roussos et al. ${ }^{38}$ that parents tend to pay more attention to emotional and social aspects of their children's problematic behaviour. The reported low to moderate levels of agreement between parents and teachers on the particular rating scale suggest that it should be used with caution to gather conclusive data on mental health problems that might affect the main ADHD symptoms.

The level of agreement between parents' and teachers' ratings on hyperactivity according to SDQ was moderate (0.31) and in line with the mean level of agreement (0.28) between multiple informants provided by Achenbach et al. ${ }^{24,26}$. Other studies have also shown the cross-cultural low levels of agreement between parents' and teachers' rating ${ }^{39-42}$. Although it has been implied that this low level of agreement might be due either to the 'reliability hypothesis' 43 or to response bias, it could be due caused by numerous factors: a) parents are not adequately informed about the actual behaviours of their children in the classroom setting ${ }^{24}$, and could be why they reported more hyperactivity than teachers; b) teachers attend to the same student on multiple occasions and with long breaks and vacations ${ }^{25}$; and c) children behave differently in diverse settings ${ }^{24}$.
Parents' and teachers' agreement on ADHD symptoms according to CAP were considerably higher, ranging from 0.60 for inattention to 0.64 for hyperactivity and 0.66 for attention deficit with hyperactivity. The argument that the distribution of subtypes of ADHD constitutes an artefact of the singleinformant methodology ${ }^{44,45}$ is not supported in the present study, since parents' and teachers' agreement for individual inattentive and hyperactive dimensions of the scale was high. Parents rated their children higher on the hyperactive and combined dimensions of the scale than teachers, while no differences were found among informants on inattentive dimension, as was observed also in other studies ${ }^{46,47}$.

The levels of agreement between scores in the hyperactivity scale of SDQ and the three dimensions of ADHD measured by CAP were fair (between 0.47 and 0.59 ) both for parents and for teachers and show that they were consistent in their reporting of symptoms across measures. However, this is partly predictable, since SDQ hyperactivity subscale includes items covering inattention, hyperactivity and impulsivity. In the present study the mean correlation between parents and teachers on hyperactivity, emotional problems, conduct problems, and peer problems was 0.433 , whereas the mean correlation among the three scales of CAP was 0.787 for parents and 0.793 for teachers. These findings indicate that disruptive behaviour scales have relatively poor discriminant and convergent validity ${ }^{48,49}$, and that measures developed in the future should protect against the halo effect.

The gender differences that have been documented in other research ${ }^{50-52}$ were also evident in the present study. Boys exhibited more symptoms of ADHD than girls; the male-to-female ratio was $3: 1$ according to the parents and 5:1 according to the teach- 
ers, matching the worldwide average gender distribution ${ }^{31,53}$. Boys were more overactive and exhibited more behavioural problems than girls, as reported also by Biederman et al., Frigerio et al., and Rowland et al. ${ }^{50-52}$; this is expected, since children who are hyperactive usually present more behavioural problems ${ }^{53}$. Girls, on the other hand, were found to be more inattentive than boys, as was documented also by Biederman et al., Hynd et al., and Skansgaard et al. ${ }^{50,54,55}$, who argued that attention problems might lead to cognitive deficits that were not assessed in the present study. Although it is possible that gender difference regarding ADHD and comorbidity reflect a more rigid gender role for boys than for girls ${ }^{56}$, they should be addressed also in the treatment that children with ADHD follow ${ }^{50}$. Although the cross-cultural gender differences in ADHD scores is well established, an interesting aspect of this study is that the gender difference persisted although the participants were randomly sampled from the classrooms.

A limitation of the present study is that there is no data on who the non-respondents were and whether they differed to some extent from respondents. For example, Rowland et al..$^{21}$ reported that some of the parents who did not participate in their study had children with many ADHD related symptoms and did not want their children to be identified and possibly stigmatised, while others did not think that the study was relevant to them ${ }^{21}$. However, the percentage of parents and teachers who completed both questionnaires was higher than $80 \%$, which is deemed necessary ${ }^{57}$. It should also be stressed that children who face more serious ADHD symptoms and other mental health problems are very likely to attend inclusion schools, which were not among the schools that were studied here.
Despite the limitations that were mentioned above, this study is -as far as we know- the first large scale epidemiological study in Greece that measures the frequency of ADHD and other mental health problems and supports the necessity to diagnose ADHD on the basis of independent reports collected both by parents and teachers, as suggested also by Tripp et al. ${ }^{58}$.

\section{References}

1. American Psychiatric Association. Diagnostic and Statistical Manual of Mental Disorders $4^{\text {th }}$ edn-TR. Washington: American Psychiatric Association; 2000.

2. Goldstein S. Understanding and managing children's classroom behaviour. New York: Wiley and sons; 1995.

3. Shaffer D. Attention deficit hyperactivity disorder in adults. Am J Psychiatry 1994; 151(5): 633-638.

4. Boyle MH, Offord DR, Racine Y, Szatmari P, Fleming JE, Sanford M. Identifying thresholds for classifying childhood psychiatric disorder: Issues and prospects. J Am Acad Child Adolesc Psychiatry 1996; 35(11): 1440-1448.

5. Vostanis P. Strengths and Difficulties Questionnaire: Research and clinical applications. Curr Opin Psychiatry 2006; 19(2): 367-372.

6. Newman DL, Moffitt TE, Caspi A, Magdol L, Silva PA, Stanton WR. Psychiatric disorder in a birth cohort of young adults: Prevalence, comorbidity, clinical significance, and new case incidence from ages 11-21. J Consult Clin Psychol 1996; 64(3): 552-562.

7. Polanczyk G, Jensen P. Epidemiologic considerations in attention deficit hyperactivity disorder: A review and update. Child Adol Psychiatric Clinics N Am 2008; 17(2): 245-260.

8. Barkley RA. Attention Deficit Hyperactivity Disorder: A Handbook for Diagnosis and Treatment $2^{\text {nd }}$ edn. New York: Guilford Press; 1998.

9. Discala C, Lescohier I, Barthel M, Li G. Injuries to children with attention deficit hyperactivity disorder. Pediatr 1998; 102(6): 1415-1421.

10. Mannuzza S, Klein RG, Bessler A. Adult outcome of hyperactive boys. Arch Gen Psychiatry 1993; 50(7): 565-576. 
11. Moffitt TE. Juvenile delinquency and attention deficit disorder: Boy's developmental trajectories from age 3 to age 15. Child Dev 1990; 61(3): 893-910.

12. Biederman J, Faraone S, Milberger S, Guite J, Mick E, Chen L, et al. A prospective 4-year follow-up study of attention-deficit hyperactivity and related disorders. Arch Gen Psychiatry 1996; 53(6): 437-446.

13. American Academy of Pediatrics. Clinical practice guideline: Diagnosis and evaluation of the child with attention-deficit/hyperactivity disorder. Pediatr 2000; 105(5): 1158-1170.

14. Shaywitz SE, Shaywitz BA. Comorbidity: A critical issue in attention deficit disorder. J Child Neurol 1991; 6(1): S13-S20.

15. Castellanos FX. Toward a pathophysiology of attention-deficit/hyperactivity disorder. Clin Pediatr 1997; 36(2): 381-393.

16. Biederman J, Mick E, Faraone SV. Depression in attention deficit hyperactivity disorder (ADHD) children: "True" depression or demoralization? J Affect Disord 1998; 47(1): 113-122.

17. Souza I, Pinheiro MA, Denardin D, Mattos P, Rohde LA. Attention-deficit/hyperactivity disorder and comorbidity in Brazil: Comparisons between two referred samples. Eur Child Adolesc Psychiatry 2004; 13(4): 243-248.

18. Rowland AS, Lesesne CA, Abramowitz AJ. The epidemiology of attention-deficit/hyperactivity disorder. Am J Ment Retard Dev Disab Res Rev 2002; 8(4): 162-170.

19. American Psychiatric Association. Diagnostic and Statistical Manual of Mental Disorders $4^{\text {th }}$ edn. Washington: Author; 1994.

20. Brunshaw JM, Szatmari P. The agreement between behaviour checklists and structured psychiatric interviews for children. Can J Psychiatry 1988; 33(4): 474-481.

21. Rowland AS, Umbach DM, Catoe KE, Stallone L, Long S, Rabiner D, et al. Studying the epidemiology of attention-deficit hyperactivity disorder: Screening method and pilot results. Can J Psychiatry 2001; 46(9): 931-940.

22. Stanger C, Lewis M. Agreement among parents, teachers, and children on internalising and externalising behavior problems. J Clin Child Psychol 1993; 22(1): 107-115.

23. Greene RW. Students with attention-deficit hyperactivity disorders and their teachers: Implications of a goodness-of-fit perspective. Adv Clin Child Psychol 1996; 18(2): 205-230.

24. de Nijs PFA, Ferdinand RF, de Bruin EI, Dekker MCJ, van Dujin CM, Verhulst FC. Attention-deficit/hyperactivity disorder (ADHD): Parents' judgement about school, teachers' judgement about home. Eur Child Adolesc Psychiatry 2004; 13(5): 315-320.

25. Biederman J, Faraone SV, Monuteaux MC, Grossbard JR. How informative are parent reports of attentiondeficit/hyperactivity disorder symptoms for assessing outcome in clinical trials of long-acting treatments? A pooled analysis of parents' and teachers' reports. Pediatr 2004; 113(6): 1667-1671.

26. Achenbach TM, McConaughty ST, Howell CT. Child/adolescent behavioural and emotional problems: Implications for cross informant correlations for situational specificity. Psychol Bull 1987; 101(1): 213-232.

27. Leung PW, Luk SL, Ho TP, Taylor E, Mak FL, Bacon-Shone J. The diagnosis and prevalence of hyperactivity in Chinese schoolboys. Br J Psychiatry 1996; 168(4): 486-496.

28. Bird H. Epidemiology of childhood disorders in a cross-cutlural context. J Child Psychol Psychiatry. 1996; 37(1): 35-49.

29. Cohen MJ, Riccio CA. Methodological differences in the diagnosis of attention-deficit hyperactivity disorder: Impact on prevalence. J Emot Behav Disord 1994; 2(1): 31-38.

30. Newcorn JH, Halperin JM, Jensen PS, Abikoff HB, Arnold LE, Cantwell DP, et al. Symptom profiles in children with ADHD: Effects of comorbidity and gender. J Am Acad Child Adolesc Psychiatry 2001; 40(1): 137-146.

31. Cantwell DP. Attention deficit disorder: A review of the past ten years. J Am Acad Child Adolesc Psychiatry 1996; 35(8): 978-987.

32. Goodman R. The Strengths and Difficulties Questionnaire: A research note. J Child Psychol Psychiatry 1997; 38(5): 581-586.

33. Barkley RA. Attention Deficit Hyperactivity Disorder: A Handbook for Diagnosis and Treatment. New York: Guilford Press; 1990.

34. Mathai J, Anderson P, Bourne A. Comparing psychiatric diagnoses generated by the Strengths and Difficulties Questionnaire with diagnoses made by clinicians. Aus N Z J Psychiatry 2004; 38(3): 639-643.

35. Wolraich ML, Hannah JN, Baumgaertel A, Feurer ID. Examination of DSM-IV criteria for attention deficithyperactivity disorder in a county-wide sample. J Dev Behav Pediatr 1998; 19(1): 162-168.

36. Obel C, Heiervang E, Rodriguez A, Heyerdahl S, Smedje H, Sourander A, et al. The Strengths and Difficulties Questionnaire in the Nordic countries. Eur Child Adolesc Psychiatry 2004; 13(1): ii32-ii39. 
37. Stalikas A, Triliva S, Roussi P. The psychometric tools in Greece: A collection and presentation of questionnaires, tests, and checklists. Athens: Hellinika Grammata; 2002.

38. Roussos A, Karantanos G, Richardson C, Hartman C, Karajiannis D, Kyprianos S, et al. Achenbach's Child Behavior Checklist and Teacher Report Form in a normative sample of Greek children 6-12 years old. Eur Child Adolesc Psychiatry 1999; 8(1): 165-172.

39. van Widenfelt BM, Goedhart AW, Treffers PD, Goodman R. Dutch version of the SDQ. Eur Child Adolesc Psychiatry 2003; 12(2): 281-289.

40. Goodman R, Meltzer H, Bailey V. The SDQ: A pilot study on the validity of the self-report version. Eur Child Adolesc Psychiatry 1998; 7(1): 125-130.

41. Muris P, Meesters C, van de Berg F. The SDQ: Further evidence for its reliability and validity in a community sample of Dutch children and adolescents. Eur Child Adolesc Psychiatry 2003; 12(1): 281-289.

42. Murray DW, Kollins SH, Hardy KK, Abikoff HB, Swanson JM, Cunningham C, et al. Parent versus teachers ratings of attention-deficit/hyperactivity disorder symptoms in the preschoolers with attention-deficit/hyperactivity disorder treatment study (PATS). J Child Adolesc Psychopharm 2007; 17(5): 605-620.

43. Fergusson DM, Lynskey MT, Horwood LJ. Conduct problems and attention deficit in middle childhood and cannabis use by age 15. Aus N Z J Psychiatry 1993; 27(3): 673-682.

44. Mitsis EM, McKay KE, Schulz KP, Newcorn JH, Halperin J. Parent-teacher concordance for DSM-IV attention-deficit/hyperactivity in a clinic-referred sample. J Am Acad Child Adolesc Psychiatry 2000; 38(3): 308-313.

45. Mugnaini D, Masi G, Brovedani P. Teacher reports of ADHD symptoms in Italian children at the end of first grade. Eur Psychiatry 2006; 21(3): 419-426.

46. Achenbach T. Manual for the Youth Self Report and Profile. Burlington: University of Vermont, Department of Psychiatry; 1987.

47. Conners CK. Rating scales in ADHD: Use in assessment and treatment monitoring. J Clin Psychiatry 1998; 59(suppl 7): S24-S30.

48. Burns GL, Walsh JA, Gomez R. Convergent and discriminant validity of trait and source effects in ADHDinattention and hyperactivity/impulsivity measures across a 3-month interval. J Abnorm Child Psychol 2003; 31(4): 529-541.

49. Gomez R, Burns GL, Walsh JA, Hafetz N. A multitrait-multisource confirmatory factor analytic approach to the construct validity of ADHD and ODD rating scales with Malaysian children. J Abnorm Child Psychol 2005; 33(3): 241-254.

50. Biederman J, Mick E, Faraone SV, Braaten E, Doyle A, Spencer T, et al. Influence of gender on attention deficit hyperactivity disorder in children referred to a psychiatric clinic. Am J Psychiatry 2002; 159(1): 36-42.

51. Gaub M, Carlson CL. Gender differences in ADHD: A meta-analysis and critical review. J Am Acad Child Adolesc Psychiatry 1997; 36(8): 1036-1045.

52. Schahar R, Tannock R. Syndromes of hyperactivity and attention deficit. In: Rutter M, Taylor E. eds. Child and adolescent psychiatry, 4th edition. New York: Blackwell Publishing; 2002. p. 399-418.

53. Edelrock C, Costello AJ, Kessler MD. Empirical correlation of the attention deficits disorders. J Am Acad Child Adolesc Psychiatry 1984; 23(2): 285-290.

54. Hynd GW, Lorys AR, Simrund-Clikeman M, Nieves N, Huettner MIS, Lahey BB. Attention deficit disorder without hyperactivity: A distinct behavioral and neurocognitive syndrome. J Child Neurol 1991; 6(1): 35-41.

55. Skansgaard EP, Burns GL. Comparison of DSM-IV ADHD combined and predominantly inattention types: Correspondence between teacher ratings and direct observation of inattentive, hyperactive/impulsivity, slow cognitive tempo, oppositional defiant and even conduct disorder symptoms. Child Fam Behav Ther 1998; 20(1): 1-14.

56. Sloboskaya HR. Competence, emotional and behavioral problems in Russian adolescents. Eur Child Adolesc Psychiatry 1999; 8(1): 173-180.

57. Fitzpatrick C, Deehan A. Competencies and problems of Irish children and adolescents. Eur Child Adolesc Psychiatry 1999; 8(1): 17-23.

58. Tripp G, Schaughency EA, Clarke B. Parent and teacher rating scales in the evaluation of attention-deficit hyperactivity disorder: Contribution to diagnosis and differential diagnosis in clinically referred children. J Dev Behav Disord 2006; 27(3): 209-218.

Address for correspondence:

Dr. Vaya Papageorgiou, M.D.,

Department of Psychiatry,

University of Ioannina School of Medicine,

Dourouti - Ioannina 45100 - Greece

Tel: +30-26510 99844-99306;

Fax: +30 2651099667

E-mail: vpapag@cc.uoi.gr 